\title{
Fabrication and Study of the Organic-Inorganic Semiconductor Diodes Formed on $n$-Si
}

\author{
B. Vengalis ${ }^{a, *}$, K. Šliužiené ${ }^{a}$, V. Lisauskas ${ }^{a}$, G. Grigaliūnaité-VonseviČienĖ $\dot{E}^{b}$ \\ R. Butkuté ${ }^{c}$, R. LyGaitis ${ }^{c}$ And J.V. GRaŽUleviČIUSS ${ }^{c}$ \\ ${ }^{a}$ Semiconductor Physics Institute, Center for Physical Sciences and Technology, Goštauto 11, LT 01108 Lithuania \\ ${ }^{b}$ Vilnius Gediminas Technical University, Saulètekio al. 11, LT-10223 Vilnius, Lithuania \\ ${ }^{c}$ Faculty of Chemical Technology, Kaunas University of Technology, Radvilenu 19, LT-50254, Kaunas, Lithuania
}

\begin{abstract}
We report fabrication and electrical characterization of the organic-inorganic semiconductor diode structures formed by evaporating thin films of three novel low molecular mass organic compounds on $n$-type Si substrates. The organic compounds containing carbazole and triphenylamine structural units, namely: 9,9'-bis(4-butylphenyl)-3,3'-bicarbazolyl (BPBC), 4-(1H-perimidin-2-yl)- $N, N$-diphenylbenzenamine (PER) and 9, $9^{\prime}$-diethyl-3,3'-bicarbazolyl (EBC) have been synthesized. The current-voltage characteristics of the $\mathrm{Au} /(\mathrm{BPBC}, \mathrm{EBC}, \mathrm{PER}) / n$-Si diode structures measured at $T=295 \mathrm{~K}$ revealed rectifying behavior with a potential barrier height values of $0.71 \mathrm{eV}$, $0.73 \mathrm{eV}, 0.76 \mathrm{eV}$, respectively.
\end{abstract}

PACS: 73.61.Ph, 73.40.Lq, 73.40.Ei, 73.40.Ns

\section{Introduction}

Electronic devices based on organic semiconductors (OS) [1] such as organic light emitting diodes (OLED), organic thin film field-effect transistors (OTFT) [2] offer an attractive alternative to conventional inorganic devices due to their potential use for large-area electronics. Mechanical flexibility of OS makes them more compatible for use with plastic substrates for lightweight and foldable applications.

In this study, we report fabrication and electrical characterization of the organic-inorganic semiconductor diodes based on thin films of three novel OS compounds. The $\mathrm{Au} / \mathrm{OS} / n$-Si device structures were formed on $n$-type $\mathrm{Si}$ substrates with carrier density of about $10^{17} \mathrm{~cm}^{-3}$. Electrical characteristics of the device structures have been investigated to estimate major electrical parameters and to define their possible use for electronic applications.

\section{Experimental}

Three new low molecular mass organic compounds containing carbazole and triphenylamine structural units, namely: 9,9'-bis(4-butylphenyl)-3,3'-bicarbazolyl (BPBC), 4-(1H-perimidin-2-yl)$-N, N$-diphenylbenzenamine (PER) and 9,9'-diethyl-3,3'-bicarbazolyl (EBC) have been synthesized and characterized recently by technology group from Kaunas

\footnotetext{
* corresponding author; e-mail: veng@pfi.lt
}

University of Technology [3]. The BPBC, EBC and PER films with thickness ranging from about $250 \mathrm{~nm}$ to $300 \mathrm{~nm}$ were thermally evaporated in vacuum $\left(p \approx 4 \times 10^{-6}\right.$ Torr) onto phosphorus-doped non-heated $\mathrm{Si}$ wafers with polished (111) surface using resistively heated tantalum boats. Distance between the substrates and the evaporator was about $10 \mathrm{~cm}$. Thickness $d$ of the as prepared OS films has been measured by DECTAC profilometer while surface morphology of the films was characterized by an atomic force microscope.

To prepare the diode structures, isolating $\mathrm{SiO}_{2}$ layer with thickness of about $0.2 \mu \mathrm{m}$ has been grown onto the surface of $\mathrm{Si}$ substrates by oxidation. In following, an array of windows with the area of $2 \times 2 \mathrm{~mm}^{2}$ was formed on a top of the oxidized Si substrates by a standard photolithography technique and subsequent HF etching to obtain the OS/Si diode structures as shown in the inset to Fig. 1. Finally, metallic $(\mathrm{Au})$ electrodes were thermally evaporated onto the OS films through a shadow mask to define an active area of the top electrodes $\left(S \approx 3-4 \mathrm{~mm}^{2}\right)$ while In-Ga alloy attached to the backside of $\mathrm{Si}$ substrates was used as low electrical resistance bottom electrode. Current-voltage $(I-U)$ characteristics of the prepared (BPBC, EBC, PER) $n$-Si diode structures have been measured at temperatures ranging from $295 \mathrm{~K}$ up to $250 \mathrm{~K}$ using Keithley 2002 multimeter and Agilent $6633 \mathrm{~B}$ programmable DC power supply.

\section{Results and discussion}

All the diode structures formed on $n$-type Si with removed native oxide exhibited nonlinear current-voltage 


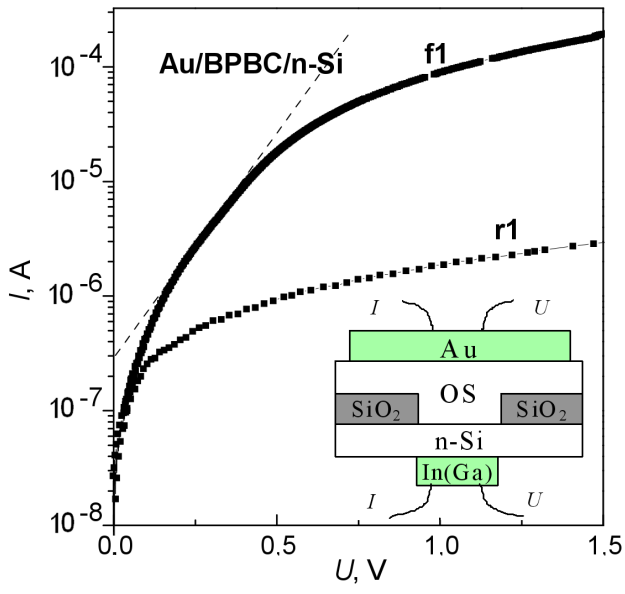

Fig. 1. Typical forward (f1) and reverse (r1) currentvoltage characteristics of the $\mathrm{Au} / \mathrm{BPBC} / n$-Si device structure measured at $T=295 \mathrm{~K}$. The dotted fitting line demonstrates exponential growth behavior following the Schottky law. Schematic view of the device structure is displayed in the inset.

characteristics and clearly defined rectifying properties. In Fig. 1 and Fig. 2 we show typical forward (curves f1) and reverse (curves $\mathrm{r} 1$ ) bias semi-log plots of currentvoltage $(I-U)$ characteristics measured at room temperature $(T=295 \mathrm{~K})$ for the $\mathrm{Au} / \mathrm{BPBC} / n-\mathrm{Si}$ and $\mathrm{Au} / \mathrm{EBC} /$ $n$-Si device structures, respectively. Let us note that forward current direction for the heterostructures corresponded to a positive voltage applied to the top $(\mathrm{Au})$ electrodes evaporated onto the organic layers. It can be seen from the figures that linear $I-U$ relations have only been certified for the diode structures at relatively low bias voltages $(|U| \leq 0.1 \mathrm{~V})$. Meanwhile nonlinear $I-U$ behavior typical for the Schottky barrier diodes has been indicated at higher voltage values $(|U| \geq 0.1 \mathrm{~V})$.

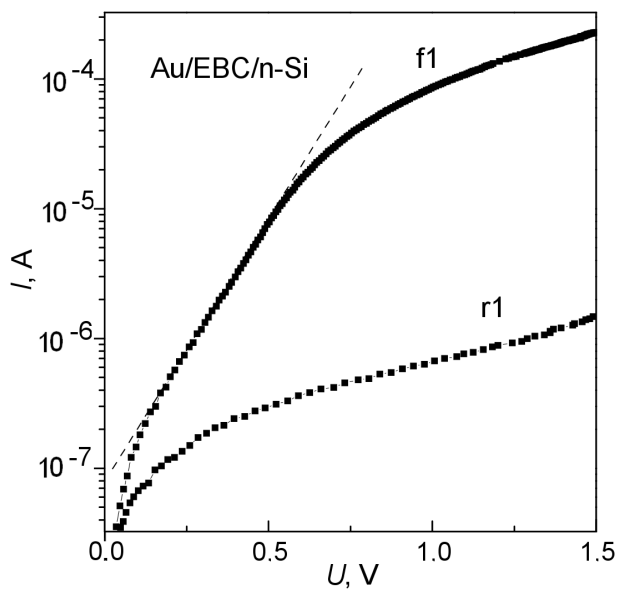

Fig. 2. Forward (f1) and reverse (r1) current-voltage characteristics of the $\mathrm{Au} / \mathrm{EBC} / n$-Si device structure measured at $T=295 \mathrm{~K}$.
In Fig. 1 and Fig. 2, one can see clearly defined linear regions in the displayed $\lg I_{\mathrm{f}}-U_{\mathrm{f}}$ plots (see the corresponding dotted lines). Values of the characteristic rectification ratio $K_{\mathrm{r}}=I_{\mathrm{f}} / I_{\mathrm{r}}$ of about 50 and 120 (at $U= \pm 1.0 \mathrm{~V}$ ) can be estimated from the figures for the $\mathrm{Au} / \mathrm{BPBC} / n$-Si and $\mathrm{Au} / \mathrm{EBC} / n$-Si diode structures, respectively. Slight shift of the measured $\lg I_{\mathrm{f}}-U_{\mathrm{f}}$ plots to higher voltage values and certain decrease of the reverse current have been indicated for the heterostructures with temperature decreasing. However, in both cases, the relationship $I_{\mathrm{f}}>I_{\mathrm{r}}$ (at fixed $|U|$ values) was found to be valid in the hole temperature range.

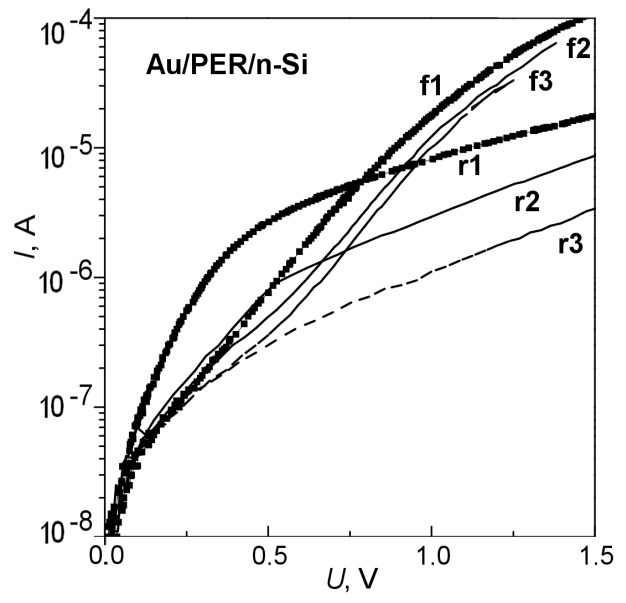

Fig. 3. Forward (f1, f2, f3) and reverse (r1, r2, r3) current-voltage characteristics of the $\mathrm{Au} / \mathrm{PER} / n$-Si device structure measured at $T=295 \mathrm{~K}(\mathrm{f} 1, \mathrm{r} 1), 273 \mathrm{~K}$ $(\mathrm{f} 2, \mathrm{r} 2)$ and $250 \mathrm{~K}(\mathrm{f} 3, \mathrm{r} 3)$.

The $I-U$ characteristics of the $\mathrm{Au} / \mathrm{PER} / n$-Si heterostructure measured at $T=295 \mathrm{~K}, 273 \mathrm{~K}$ and $250 \mathrm{~K}$ in a case of a forward and reverse bias (curves f1, f2, f3 and r1, r2, r3, respectively) are displayed in Fig. 3. Linear regions in the $\lg I_{\mathrm{f}}-U_{\mathrm{f}}$ plots can be seen from the figure although it is important to note significantly higher $I_{\mathrm{f}}$ values compared to those measured at the same conditions for the $\mathrm{Au} / \mathrm{BPBC} / n-\mathrm{Si}$ and $\mathrm{Au} / \mathrm{EBC} / n-\mathrm{Si}$ diode structures. At room temperature (curves $\mathrm{f} 1$ and r1 in Fig. 3), the $\mathrm{Au} / \mathrm{PER} / n$-Si heterostructure demonstrated relatively low values of the rectification ratio $\left(K_{\mathrm{r}} \approx 3\right.$ at $\left.U= \pm 1.0 \mathrm{~V}\right)$ while at lower bias values $(0.1<U<0.7 \mathrm{~V}), K_{\mathrm{r}}<1\left(I_{\mathrm{f}}<I_{\mathrm{r}}\right)$ have been indicated. Significant decrease of the reverse bias current has been observed with temperature decreasing while at $T=250 \mathrm{~K}$ (curves $3 \mathrm{f}$ and $3 \mathrm{r}$ in Fig. 3 ) the $I_{\mathrm{r}}$ values were found to be lower than those of $I_{\mathrm{f}}$ in the whole range of voltages.

The exponential growth of current with a forward bias observed in this work for the $\mathrm{Au} /(\mathrm{BPBC}, \mathrm{EBC}, \mathrm{PER}) /$ $n$ - $\mathrm{Si}$ ) heterostructures (see linear regions in Figs. 1-3) show that they behave like a Schottky diode (metalsemiconductor junction) with a certain potential barrier occurring at the interface between the organic (BPBC, 
EBC, PER) and inorganic ( $\mathrm{Si}$ ) semiconductors.

Carrier transport in the prepared (BPBC, EBC, PER/ $n$-Si) heterostructures has been modeled taking into account dominating role of the Schottky thermoionic emission. Current flowing through a uniform interfacial barrier due to the thermoionic emission, with applied forward bias, can be expressed as [4]:

$$
\begin{aligned}
& I_{\mathrm{f}}=I_{0}\left[\exp \left(\frac{q\left(U_{\mathrm{f}}-I R_{\mathrm{s}}\right)}{n k T}\right)-1\right], \\
& I_{0}=A A^{*} T^{2} \exp \left(-\frac{q \Phi_{\mathrm{b}}}{k T}\right) .
\end{aligned}
$$

Here $I_{0}$ is the saturation current, $q$ is the electron charge,
$U$ is the forward bias voltage, $R_{\mathrm{S}}$ is series resistance, $n$ is ideality factor ( $n=1$ for an ideal contact), $k$ is the Boltzmann constant, $T$ - the absolute temperature. $A$ is the effective area of the device structure, $A^{*}$ is the effective Richardson constant $\left(112 \mathrm{~A} \mathrm{~cm}^{-2} \mathrm{~K}^{-2}\right.$ for $n$-type Si [5]).

The effective activation energy $\Phi_{\mathrm{b}}$ (zero-bias barrier height) has been obtained in this work from Eq. (2) while $I_{0}$ has been derived from the current axis intercept of the linear region in the forward bias $\left(\ln I_{\mathrm{f}}-U_{\mathrm{f}}\right)$ plots. The averaged experimental values of the barrier height, $\Phi_{\mathrm{b} 0}$, the ideality factor, $n$, and the saturation current density, $I_{0}$, estimated from the measured $\lg I_{\mathrm{f}}-U_{\mathrm{f}}$ characteristics are summarized in Table.

TABLE

Major electrical parameters of the $\mathrm{Au} /(\mathrm{BPBC}, \mathrm{EBC}, \mathrm{PER}) / n$-Si heterostructures derived from their forward bias $I_{\mathrm{f}}-U_{\mathrm{f}}$ plots.

\begin{tabular}{l|c|c|c|c}
\hline \hline Heterostructures & $\begin{array}{c}\text { Thickness } \\
\text { of OS layer } d \\
{[\mathrm{~nm}]}\end{array}$ & $\begin{array}{c}\text { Ideality } \\
\text { factor } n\end{array}$ & $\begin{array}{c}\text { Barrier } \\
\text { height } \Phi_{\mathrm{b}} \\
{[\mathrm{eV}]}\end{array}$ & $\begin{array}{c}\text { Saturation } \\
\text { current density } I_{0} \\
{\left[\mathrm{~A} / \mathrm{cm}^{2}\right]}\end{array}$ \\
\hline $\mathrm{Au} / \mathrm{BPBC} / n-\mathrm{Si}$ & 300 & 4.0 & 0.71 & $2.9 \times 10^{-7}$ \\
$\mathrm{Au} / \mathrm{EBC} / n-\mathrm{Si}$ & 250 & 4.1 & 0.73 & $1 \times 10^{-7}$ \\
$\mathrm{Au} / \mathrm{PER} / n-\mathrm{Si}$ & 280 & 5.9 & 0.76 & $3 \times 10^{-8}$
\end{tabular}

Certain curvature downward in the forward $I_{\mathrm{f}}-U_{\mathrm{f}}$ plots at sufficiently large applied voltages seen in Figs. 1-3 may be explained taking into account a series resistance, i.e. resistance of substrate, organic layers and interfaces. Relatively high values of the ideality factor $n$ can be related to significant influence of bulk resistance of the organic layers in comparison to that of the organic-inorganic semiconductor interfaces [6]. Finally, we point out significant difference in reverse bias $I-U$ characteristics of the $\mathrm{Au} / \mathrm{PER} / n$-Si heterostructures compared to those measured for the $\mathrm{Au} /(\mathrm{BPBC}, \mathrm{EBC}$, $\mathrm{PER}) / n$-Si diodes. Unusually high reverse bias current values $\left(I_{\mathrm{r}}>I_{\mathrm{f}}\right)$ measured for the $\mathrm{Au} / \mathrm{PER} / n$-Si device structure at low voltages could be indication of bipolar conductivity of the PER organic compound at high temperatures $(T>250 \mathrm{~K})$.

\section{Conclusions}

In conclusion, $\mathrm{Au} /(\mathrm{BPBC}, \mathrm{EBC}, \mathrm{PER}) / n$-Si heterostructures have been prepared by thermal evaporation of the organic compounds in vacuum. Forward bias $I-U$ characteristics of the diode structures were found to follow the Schottky thermoionic emission model. Major electrical parameters, i.e. the barrier height $\Phi_{\mathrm{b}}$ of $0.71 \mathrm{eV}$,
$0.73 \mathrm{eV}, 0.76 \mathrm{eV}$ and the ideality factor $n$ of 4.0, 4.1, 5.9 have been estimated, respectively, for the $\mathrm{Au} /(\mathrm{BPBC}$, EBC, PER) $/ n$-Si heterostructures.

\section{Acknowledgments}

This work has been supported partially by Lithuanian Science Foundation (grant N 301-P59).

\section{References}

[1] A. Facchetti, Mater. Today 10, 28 (2007).

[2] S. Hüttner, M. Sommer, U. Steiner, M. Thelakkat, Appl. Phys. Lett. 96, 073503 (2010).

[3] R. Lygaitis, J.V. Grazulevicius, V. Gaidelis, V. Jankauskas, J. Sidaravicius, Z. Tokarski, N. Jubran, Mol. Cryst. Liq. Cryst. 427, 407 (2005).

[4] I.D. Parker, J. Appl. Phys. 75, 1656 (1994).

[5] Ö. Güllü, Ş. Aydoğan, M. Biber, A. Türüt, Vacuum 82, 1264 (2008).

[6] A.R.V. Roberts, D.E. Evans, Appl. Phys. Lett. 86, 072105 (2005). 